\title{
COMPARISON OF RADIO RESOURCE MANAGEMENT IN GSM
}

\author{
Alam N. Shaikh ${ }^{1}$ and Dr. S. K. Bodhe ${ }^{2}$ \\ ${ }^{1}$ Research Scholar, NMIMS, Mumbai, INDIA \\ alamshaikh65egmail.com \\ ${ }^{2}$ Director, Bosh Technologies, Pune, INDIA \\ s_k_bodhe@yahoo.co.in
}

\begin{abstract}
As the stipulate for wireless communication has been mounting hurriedly, resourceful management of radio spectrum becomes very imperative. Channels are derisory and hence must be utilized inventively. In this paper, a evaluation of Fixed Channel allocation and Dynamic Channel Allocation is evaluated using analytical and simulation model in 25 cell system for GSM 1800. A suitable analytical model has shored up simulation performance characteristics. The result signifies that dropping probability also decreases in FCA -HOR as call arrival rate decrease. Also it is noted that unrealizable handoffs will be discarded by based handoff decision.
\end{abstract}

\section{Keywords}

FCA, HCDP, Guard Channels, Reservation Policy.

\section{INTRODUCTION}

Fixed Channel Allocation (FCA) systems allocate specific channels to specific cells. This allocation is static and cannot be changed. For efficient operation, FCA systems typically allocate channels in a manner that maximizes frequency reuse. Thus, in a FCA system, the distance between cells using the same channel is the minimum reuse distance for that system. The problem with FCA systems is quite simple and occurs whenever the offered traffic to a network of base stations is not uniform. Consider a case in which two adjacent cells are allocated $N$ channels each. There clearly can be situations in which one cell has a need for $N+k$ channels while the adjacent cell only requires $N-m$ channels (for positive integer's $k$ and $m$ ). In such a case, $k$ users in the first cell would be blocked from making calls while $m$ channels in the second cell would go unused. Clearly in this situation of non-uniform spatial offered traffic, the available channels are not being used efficiently. FCA has been implemented on a widespread level to date. Here an unambiguous relationship is assumed between each channel and each cell, in accordance to co-channel reuse constraints. The total number of available channels in the system is divided into sets. One set of channels forms a cell, and number of set will be equal to DOI : $10.5121 /$ ijdps.2011.2614 
the cluster size. In the simple FCA strategy, the same number of nominal channels is allocated to each cell. This uniform channel distribution is efficient if the traffic distribution of the system is uniform. In that case, the overall average blocking probability of the mobile system is the same as the call blocking probability in a cell. Traffic in cellular the cluster size. In the simple FCA strategy, the same number of nominal channels is allocated to each cell. This uniform channel distribution is efficient if the traffic distribution of the system is uniform. In that case, the overall average blocking probability of the mobile system is the same as the call blocking probability in a cell. Traffic in cellular systems can be no uniform with temporal and spatial fluctuations; hence a uniform allocation of channels to cells may result in high blocking in some cells, while others might have a sizeable number of spare channels [2]. This could result in poor channel utilization. It is therefore appropriate to adapt the number of channels in a cell to match the load in it by using Dynamic Channel Allocation (DCA) and/or Hybrid Channel Allocation (HCA) [1]. Although the DCA \& HCA schemes can adapt channel assignment to dynamic traffic loads, it can also significantly increase network complexity due to co channel cell locking and signaling overheads, because it is a call-by-call based assignment [4]. It is necessary to keep both, co channel interference and adjacent channel interference, under a certain threshold. This is achieved by restricting cells within the required minimum channel reuse distance from a cell that borrows a channel from the central pool DCA also requires fast real-time signal processing and associated channel database updating [3]. In this paper uniform traffic is assumed hence FCA technique is used. This paper is mainly center of attention on handling handoffs. In general, the handoff event is caused by the radio link degradation or initiated by the system that rearranges radio channels in order to avoid congestion. In this paper the focus is given on the first kind of handoff, where the cause of handoff is poor radio quality due to a change in the environment or the movement of the wireless terminal. The mobile subscriber is crossing the cell boundary, while the call is in process, the call must be handed off to the neighboring cell in order to provide uninterrupted service to the mobile subscriber. If adjacent cells do not have enough channels to support the handoff, the call is forced to be dropped. An important issue is to limit the probability of forced call termination, because from the point of view of a mobile user forced termination of an ongoing call is less desirable than blocking a new call. Therefore, the system must reduce the chances of unsuccessful handoffs by reserving some channels explicitly for handoff calls. Handoff prioritizing schemes provide improved performance at the cost of reduction in the total admitted traffic, in turn an increase in the blocking probability of new calls. The simplest way of giving priority to handoff calls is to reserve some channels for handoff calls explicitly in each cell [3]. This scheme is referred to as the cutoff priority scheme (CPS) or the guard channel scheme (GCS). Other prioritizing schemes allow either the handoff to be queued or new calls to be queued until new channels are obtained in the cell. The guard channel concept can also be used in DCA or HCA schemes. Here guard channels are not assigned to cells permanently; instead, the system can keep a collection of channels to be used only for handoff requests, or have a number of flexible channels with associated probabilities of being allocated for handoff requests. Pertinent work and Problem Definition is discussed in Section 2, Analytical 
Model is discussed in Section 3, Results and Conclusions are discussed in section 5 and 6 respectively.

\section{Relevant Work and Problem Definition}

Generally, the size of cell is not the same and various decisions regarding Absolute Radio Frequency Channel Numbers (ARFCN) allotment are made on practically gathered data. Algorithms discussed in [5-6] talk about different ways for channel assignment to reduce call blocking. [8,9] considers the ACCT for channel allocation. The improvement in the blocking probability of the heavy loaded cell is studied as a function of the arrival rate of the low traffic cell. In the light of this work and depending upon the structure of a particular network, an optimum way can be found to allot the channels to various cells or to reshuffle them. Adjacent channel interference is another important parameter that needs to be considered in grouping the channels with the proposed scheme. This scheme still needs some modification.. An Evolutionary Strategy (ES) is developed in [10], which optimizes the channel assignment. ES based algorithm has the advantage of producing reliable solutions in a smaller number of call generation as compared to other heuristics such as genetic algorithm. A novel hybrid channel assignment based scheme called D-ring is developed in [10]. The advantage of the representation proposed in [10] over the others is that it reduces the computation time involved in the calculation of the energy when the demand of channel is less than the total number of available channels. Using the concept of neighboring area reduces the time required in the determination of co-channel interference. Handoff prioritization scheme is discussed. Here based on the class of traffic the priority for the handoff is decided. Lot of research has been done in this area. in the cell is less than or equal $S_{R}=S-S_{C}$. A handoff request is blocked if no channel is available in the target cell. The system model is shown in Fig. 1 and its State transition diagram is shown in Fig. 2.

\section{Analytical Model}

\section{System Model}

A system with multiple cells is considered in which all cells are homogeneous .Each of this cell has $S$ channels. The channel holding time has an exponential distribution with mean rate $\mu$.Both handoff and originating calls are generated in a cell according to Poisson process, with mean rate $\lambda_{o}$ and $\lambda_{h}$ respectively. An Analytical model for single cell is worked out in this paper. New calls are newly generated calls in the cell of interest. A handoff request will be generated when a channel holding Mobile Device approaches the cell with signal strength below the handoff threshold. Priority is given to handoff calls request by assigning $s_{R}$ channels exclusively for handoff calls among the $\mathrm{S}$ channels in a cell. The remaining $s_{C}=S-s_{R}$ channels are shared by both handoff request and originating calls. An originating call is blocked if the number of available channels in the cell is less than or equal to $s_{R}=s-s_{C}$. A handoff request is blocked if no cell channel is available in the target cell .The system model is shown in fig. 1 and its State transition diagram is shown in Fig. 2. 
International Journal of Distributed and Parallel Systems (IJDPS) Vol.2, No.6, November 2011

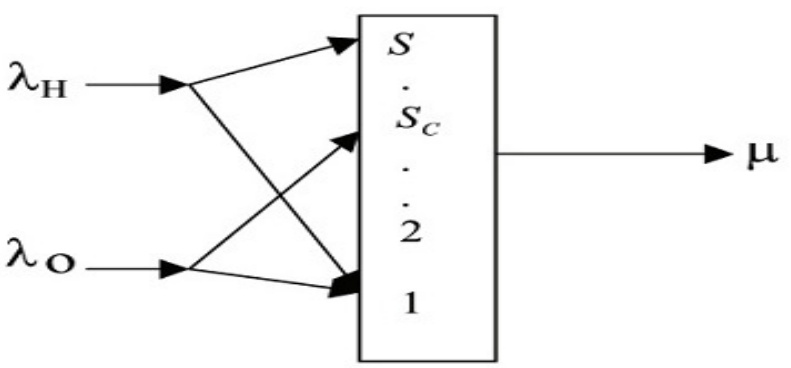

Figure 1. System model with priority for handoff

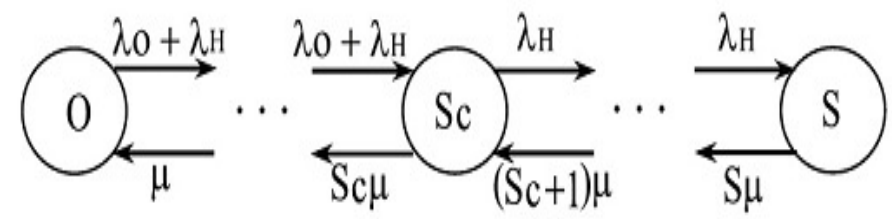

Figure 2. State Transition Diagram

The equations are-

$$
\begin{aligned}
& i \mu P(i)=\left(\lambda_{O}+\lambda_{H}\right) P(i-1), \quad, O \leq 1 \leq S_{C} \\
& i \mu P(i)=\lambda_{H} P(i-1), \quad S_{C}<i \leq S \\
& i \stackrel{S}{\sum^{S}} P(i)=1
\end{aligned}
$$

Using this Eq. (1) recursively along with normalized condition given in (2). The steady state probability $P(i)$ is easily found as mentioned in (3) where $P(0)$ is calculated by using (4):

$$
P(i)=\left\{\begin{array}{c}
\frac{\left(\lambda_{O}+\lambda_{H}\right)}{i ! \mu^{i}} P(O), \quad O \leq i \leq S_{C} \\
\frac{\left(\lambda_{O+\lambda_{H}}\right)^{S_{C} \lambda_{H}^{i-S_{C}}}}{i ! \mu^{i}} P(O), \quad S_{C} \leq i \leq S
\end{array}\right.
$$


International Journal of Distributed and Parallel Systems (IJDPS) Vol.2, No.6, November 2011

$$
P(O)=\left[\sum_{i=O}^{S} \frac{\left(\lambda_{O}+\lambda_{H}\right)^{i}}{i ! \mu^{i}}+\sum_{i=S_{C}+1}^{S} \frac{\left(\lambda_{O+\lambda_{H}}\right)^{S_{C}} \lambda_{H}^{i-S_{C}}}{i ! \mu^{i}}\right]
$$

The blocking probability $\mathrm{Pb}$ for originating call is calculated by (5)

$$
\mathrm{Pb}=\sum_{\mathrm{i}=\mathrm{s}}^{S} P(\mathrm{i})
$$

The blocking probability pd of a handoff request is given by (6)

$$
P d=P(S)=\frac{\left(\lambda_{O}+\lambda_{H}\right)^{S} C \lambda_{H}{ }^{S-S_{C}}}{S ! \mu^{S}} P(O)
$$

\section{Simulation Model and Analysis}

Simulation model that is made for analysis is as follows:

The simulated wireless network consist of 25 cells each of which has four neighboring cells as shown in figure 3.The simulated wireless network consist of 25 cells each of which has four neighboring cells as shown in figure 3

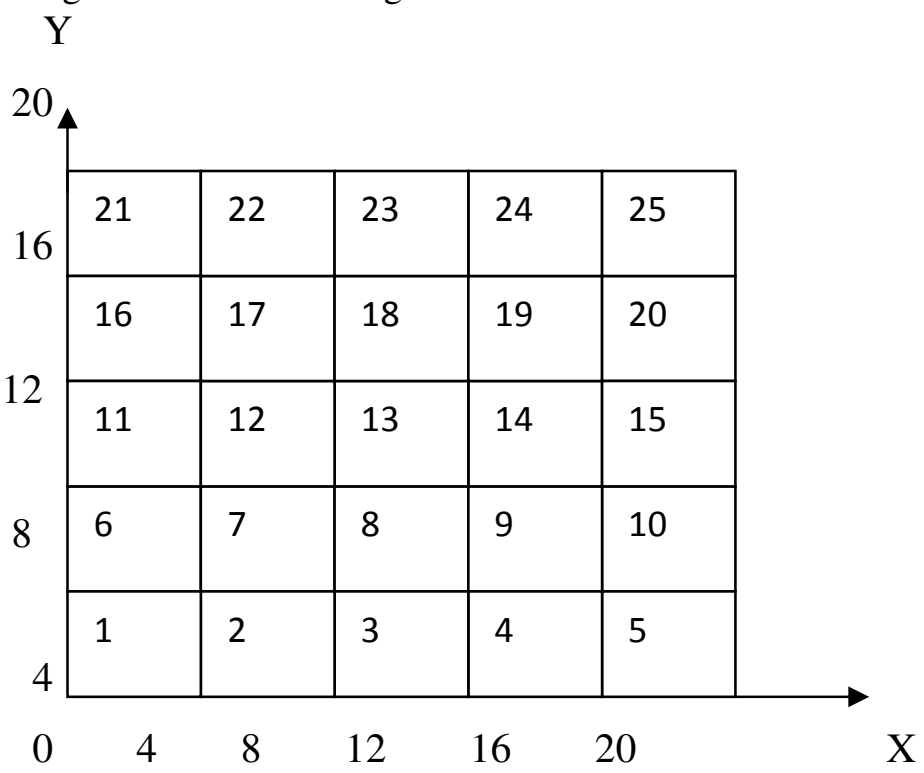

Figure 3. Simulated wireless network 
It is assumed that the top cell (Cell 21,22,23,24 and 25) and the bottom cells (Cell 1,2,3,4 and 5) are connected. That is if a user comes out of 21 from top, he will come in to cell 1. Analogously, it is assumed that the cells (cell 1, 6, 11, 16 and 21) and right cells (cell 5,10,15,20 and 25) are connected too.

Assume the base station of each cell is at the center of square. The handoff threshold can be set at any distance between cell-center to receive-threshold. The area between handoff-threshold and receive-threshold is called handoff area (shaded area of figure 4)

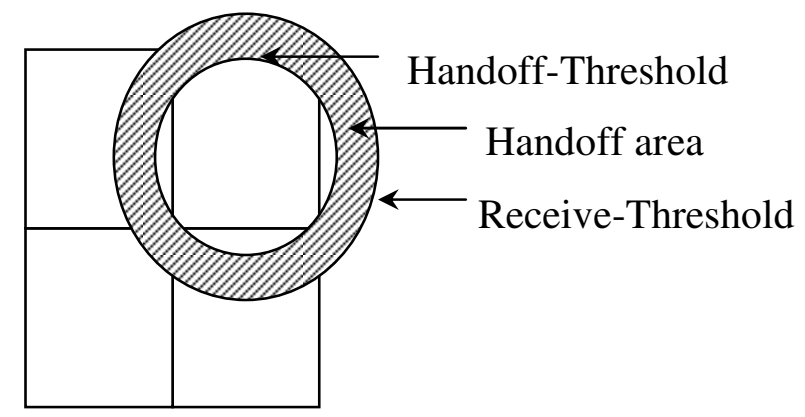

Figure 4: Handoff threshold and receive threshold.

\subsection{Simulation model}

It is developed using MATLAB ${ }^{T M}$ 7.6.

The user mobility pattern is described as follows.

When a new call request is generated, the location of the mobile users is random variable, and moving direction is chosen from uniform distribution on the interval as shown below

\begin{tabular}{|l|l|}
\hline Random Number (0-1) & Direction \\
\hline $0-0.25$ & Target cell is North cell \\
\hline $0.25-0.5$ & Target cell is East cell \\
\hline $0.5-0.75$ & Target cell is South cell \\
\hline $0.75-1$ & Target cell is West cell \\
\hline
\end{tabular}

The moving speed is uniformly distributed between 8 and $25 \mathrm{~m} / \mathrm{sec}$. The user's location and RSS is monitored at every second.

\subsection{Radio Propagation Model}

Radio propagation is influenced by the path loss depending on the distance, shadowing, and multipath fading. The relationship between the transmitted power and received power can be expressed as

$$
P(r)=10^{\xi / 10} . r^{-\alpha} . P_{0}
$$


Where, $\mathrm{P}(\mathrm{r})$ is the received power; $P_{0}$ is the transmitted power, $r$ is the distance from the base station to mobile, $\xi$ in decibels has a normal distribution with zero mean Following assumptions are made for simulation

1. Each cell has $C=30$ channels.

2. Cell radius $=2000 \mathrm{~m}$.

3. Arrival of new calls initiating in each cell forms a Poissions process with rate $\lambda$.

4. Call requires only one channel for service.

5. Arrival rate of new call and handoff call $\lambda=\lambda_{h}=30$.

6. $\mu_{h}=1 / 400$, and $\mu$ is varying from $1 / 600$ to $1 / 200$.

7. Traffic $=6$ to 20 .

is less than handoff threshold, at the same time if channel is available, handoff request is accepted otherwise it is blocked. Thus new blocking probability and handoff blocking probability is evaluated. Initially call request is generated in the cell, once a new call is admitted into the network, lifetime of this call is selected according to its distribution and then total number of new calls is estimated. If new calls are less than threshold, call is accepted otherwise it is blocked. Once the call is accepted the parameters of call are updated and signal strength is checked, if signal strength

\section{System Flowchart}

Flow chart of the system is shown in Fig. 5. If there is no carrier-slot available in the cell of interest, a new call request will be simply dropped. After a new call is accepted, the call completion is monitored.

The call will be terminated if its duration is completed, and resources will be released. If call is continuing, its RSS level will be monitored. If RSS level is lower than Handoff threshold then this call will be handed off to target cell. 
International Journal of Distributed and Parallel Systems (IJDPS) Vol.2, No.6, November 2011

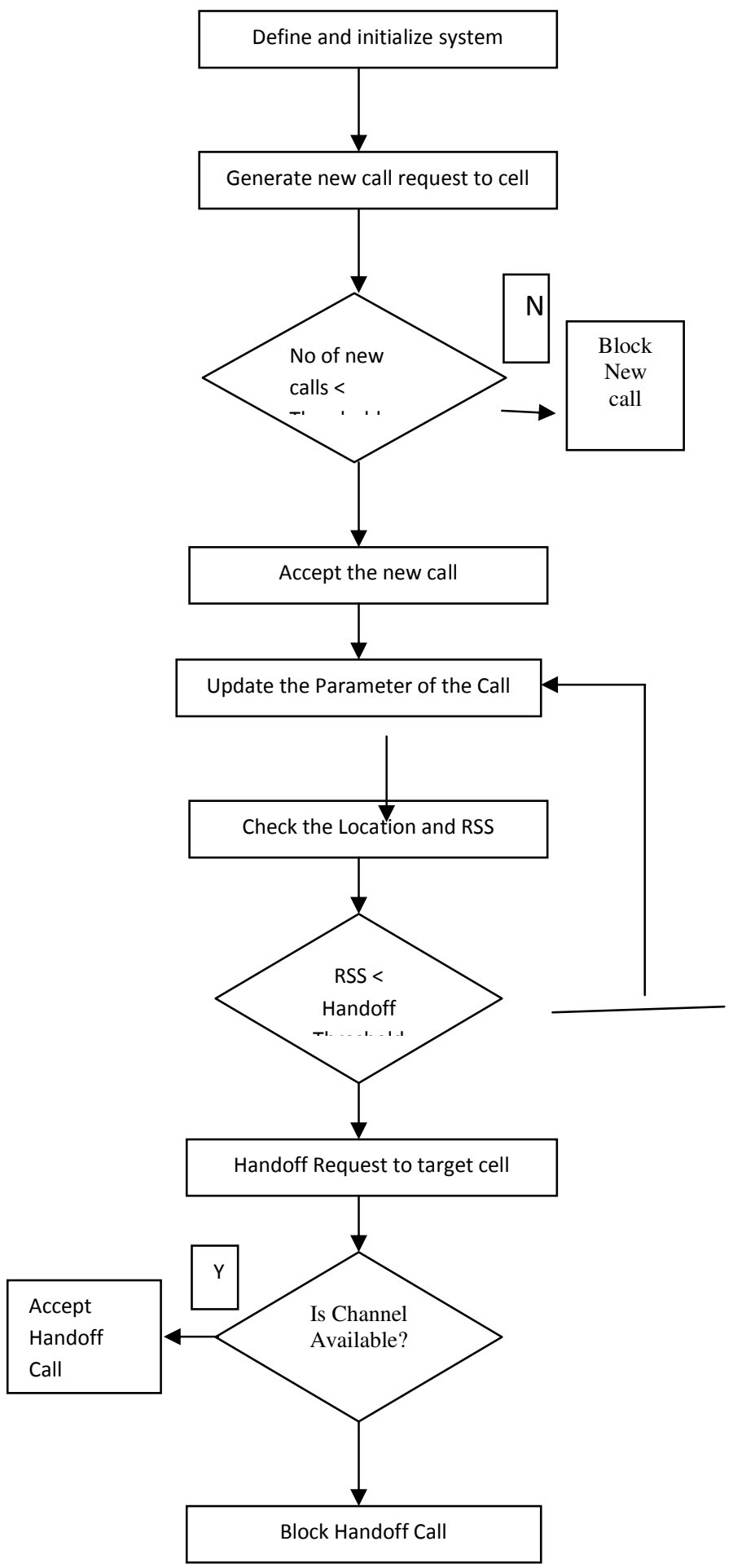

Figure 5. Flow Chart for call Threshold Scheme 
International Journal of Distributed and Parallel Systems (IJDPS) Vol.2, No.6, November 2011

Initially call request is generated in the cell, once a new call is admitted into the network, lifetime of this call is selected according to its distribution and then total number of new calls is estimated. If new calls are less than threshold, call is accepted otherwise it is blocked. Thus new blocking probability and handoff blocking probability is evaluated.

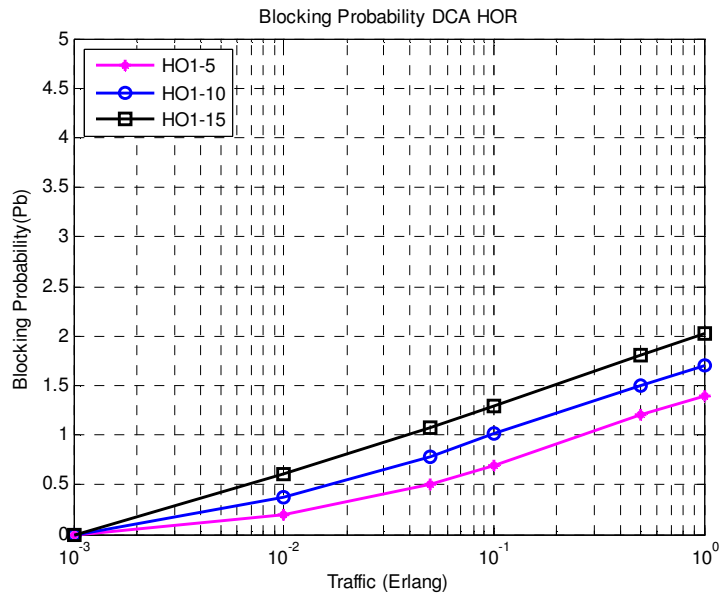

Figure 6.Blocking probability of DCA HOR

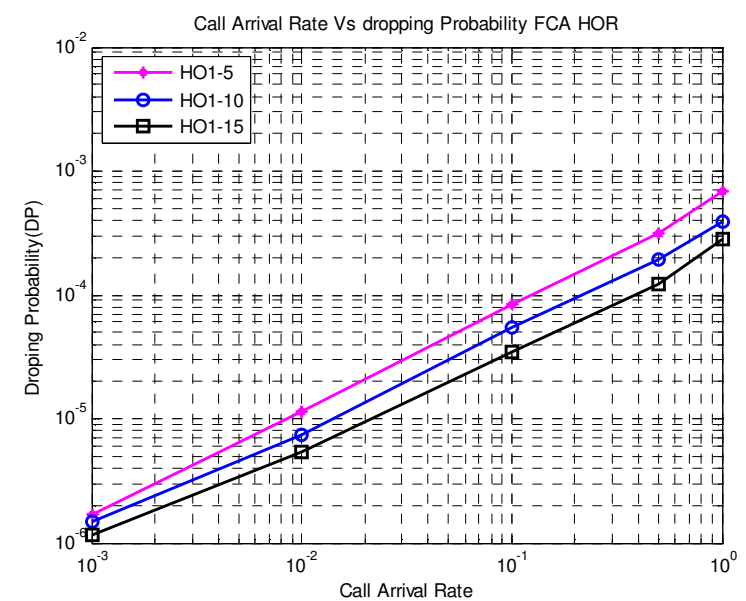

Figure 7.Call Arrival VS Dropping probability of FCA 
International Journal of Distributed and Parallel Systems (IJDPS) Vol.2, No.6, November 2011

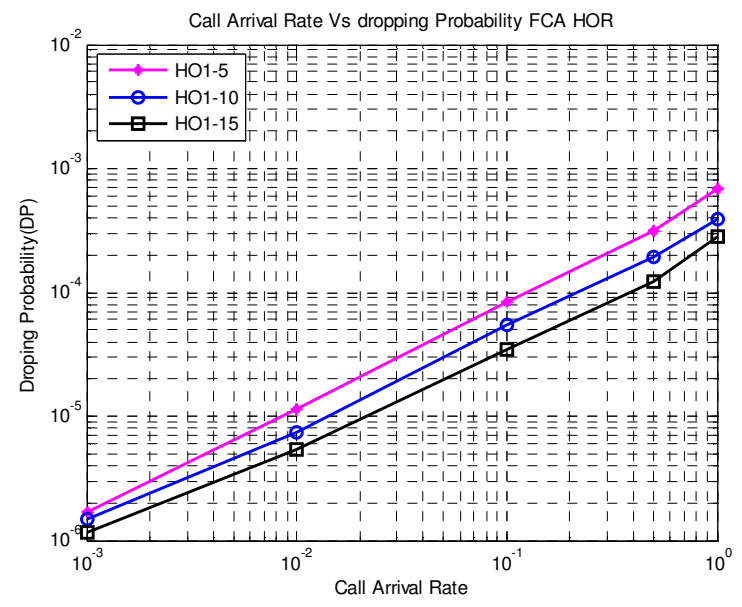

Figure 8. Blocking probability of FCA HOR

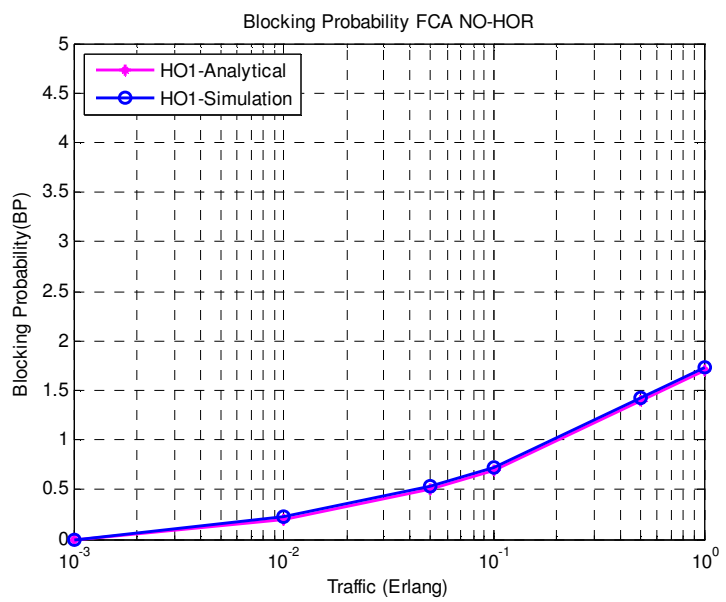

Figure 9. Blocking probability of FCA NO-HOR

\section{Conclusions}

A major challenge of the future $4 \mathrm{G}$ wireless network is the Radio Resource Management (RRM) strategy. In order to evaluate the performance of different CRRM algorithms, a simulation model needs to be developed.For GSM 1800, we have evaluated the performance of FCA and DCA.The blocking and dropping probabilities are calculated for reservation of channels for handoff calls. From the analysis and simulation. We can conclude that dropping probability for HO-reservation of $15 \%$ channels is best. The results of simulation and an analytical model indicate that as there is increase in percentage of priority channels, the handoff dropping probability reduces. The results of simulation and an analytical model indicate that as there is increase in percentage of priority channels, the handoff dropping probability reduces. Likewise, 
International Journal of Distributed and Parallel Systems (IJDPS) Vol.2, No.6, November 2011

ACCT based handoff helps in avoiding unnecessary handoffs, thus making handoff decisions only for appropriate calls, for which handoff will be realized.

\section{ACKNOWLEDGEMENTS}

I would like to express my deep and sincere gratitude to my advisor, Prof. Dr. Shrikant K. Bodhe, who

is most responsible for helping me to write this paper. His wide knowledge and logical way of thinking have been of great value for me. He was always there to meet and talk about research ideas, to proof read and markup my papers, and to ask me good questions to help me to think through my research.

I am grateful to Dr. D. J. Shah, Dean, Faculty of Engineering, and Mukesh Patel School of Technology Management and Engineering, NMIMS (Deemed-to-be-University), for his help, advice and consistent encouragement for me to do better in my research. I wish to express my sincere thanks to Shri. Amrish Patel, President, SVKM, for support to carry my research. I am greatly indebted to my father, Shri. Najir and my mother, Sou. Begam for giving me life, educating me to be an honest and responsible person. I am especially indebted to my wife Jasmin and my son Aryan, daughter Ahana, for their love and all sacrifices they have made for me. Without their positive, kind and silent support, this work would neither have been possible nor could it have been completed.

\section{REFERENCES}

[1] G. L. Stuber, "Principles of Mobile Communication", Kluwe Academic Publications, London, and 2000 ISBN: 0-79237998

[2] T. S. Rappaport, "Wireless communications: principles and practice" Pearson edition (Singapore) Pvt Ltd. ISBN: 81-7808$648-4$

[3] I. Katzela, M. Naghshineh, "Channel Assignment Schemes for Cellular Mobile Telecommunication Systems: A

Comprehensive Survey", IEEE Personal Communication June 1996, pp. 9 -31

[4] Nallasamy Mani, Tze H Lai, "Characteristics of load balancing and channel assignments in mobile Communication systems", Monash University research publication, Australia

[5] Said M. Elnoubi, Rajendra Singh, Someshwar Gupta, "A New Frequency Channel Assignment Algorithm in High Capacity

Mobile Communication Systems”, IEEE Tr. On Vehicular Technology, Vol. VT-31, No. 3, Aug 1982 pp. $125-131$.

[6] Hua Jiang, Stephen S. Rappaport, "CBWL: A New Channel Assignment and Sharing Method for Cellular Communication

Systems”, IEEE Tr. On Vehicular Technology, Vol. 43 No. 2, May 1994, pp. 313-322. Mobile Networks" IEEE Tr.

On Vehicular Technology, Vol. 54, No. 5, September 2005, pp. 1887-1895.

[7] N. D. Tripathi, J. H. Reed, and H. F. Vanlandingham, Handoff in Cellular Systems, IEEE Personal Commun.

December 1998. Mobile Telephone Systems", IEEE Transactions on Vehicular Technology, vol.38, no.4, pp211- 
International Journal of Distributed and Parallel Systems (IJDPS) Vol.2, No.6, November 2011

215, 1989.

[8] W.K. Lai and G.C. Coghill, "Channel Assignment through Evolutionary Optimization", IEEE Transactions on

Vehicular Technology, vol.45, no.1, pp91-96, 1996.

[9] L.J. Cimini and G.J. Foschini, "Distributed Algorithms for Dynamic Channel Allocation In

Microcellular Systems", IEEE Vehicular Technology Conference, pp.641-644, 1992.

[10] Geetali Vidyarthi, Alioune Ngom, Ivan Stojmenovic, "A Hybrid Channel Assignment Approach Using an Efficient

Evolutionary Strategy in Wireless

[11] S.Hurley, "Planning Effective Cellular Mobile Radio Networks", IEEE Transactions on Vehicular

Technology, vol.51, no.2, pp.254-253,2002.

[12] Qing-A Zeng, Dharma P. Agrawal, "Handoff in Wireless Mobile Networks" in Ivan Stojmenovic, "Handbook of Wireless

Networks and Mobile Computing", Edited by, John Wiley \& Sons, Inc.2002, ISBN: 0-471-419028, pp. 1-26.

[13] P.Cherriman, F.Romiti and L.Hanzo, "Channel Allocation for Third-generation Mobile Radio Systems", ACTS'98,

vol.1, Pp.255-261, 1998

[14] S.Jordan, "Resource Allocation in Wireless Networks", Journal of High Speed Networks, vol.5,

no.1, Pp.23- 24, 1996

[15] M. Salamah and H.Lababidi, "Dynamically adaptive channel reservation scheme for cellular networks",

Elsevier Computer networks, article in press, 2005

[16] A dynamic channel assignment simulation system for large scale cellular telecommunications, "P.M.Papazoglou

\section{D.A.Karras, R.C.Papademetriou"}

[17] D. Hong and S. S. Rappaport, Traffic model and performance analysis for cellular mobile radio telephone Systems

With prioritized and no prioritized handoff procedures, IEEE Trans. Veh. Technol., Vol. VT-35, No. 3, pp. 448-461, August 1986.

[18] Mauley and Pautet "GSM Radio Resource Management"

[19] Dynamic radio resource management in GSM/GPRS using scalable resource allocation technique, 2004 IEEE $15^{\text {th }}$

Symposium on personal Indoor and Mobile Radio Communications, vol 4,ISBN 0-7803-8523-3.

[20] A system level simulation model for common radio resource management, Communications, 2009. APCC

2009.15thAsia-Pacific Conference. 


\title{
Authors.
}

Short Biography

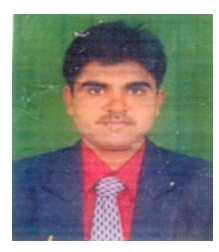

\begin{abstract}
Alam N. Shaikh received B.E. (Electronics) and M.E. (Electronics) in 1994 and 2007 respectively from Shivaji University Kolhapur; Currently he is pursuing $\mathrm{Ph}$. D. in Electronics and Telecommunications at NMIMS University, Mumbai. He is working as an Asst. Prof. in Mumbai. He has Guided 9 Post Graduate students .His research interests are Wireless Networks, Mobile Communication. He has published over 18 papers in national/international journals/Conferences. He is life member of ISTE.
\end{abstract}

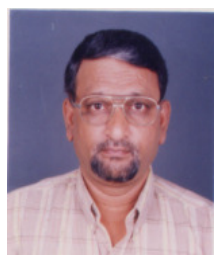

Dr. Shrikant Bodhe was born in September 19, 1959. He completed his Bachelors degree in Electronics and Telecommunication in 1983 from Pune University. He completed his Masters Degree in Electronics Engineering from Shivaji University, Kolhapur, in 1989. He received his Ph. D., in Mobile Communication from Shivaji University, Kolhapur, in 1999. He is working as a Principal; at College of Engineering Pandharpur, INDIA He has many national and International publications on his name. His research interests include Mobile Communication, Wireless ad hoc networking Wireless Sensor Networks. He has Guided 40 post Graduate students. Under his Supervision 8students have completed their Ph.D. work in the field of mobile communication. He is a member of IEEE. He has published over 80 papers in national/international journals/Conferences. 